\title{
BOUNDING THE GLOBAL WAR ON TERRORISM
}

\author{
Jeffrey Record
}

December 2003 